\title{
Spatial impacts of inorganic ligand availability and localized microbial community structure on mitigation of zinc laden mine water in sulfate-reducing bioreactors
}

\author{
Dina M. Drennan ${ }^{a, 1}$, Robert Almstrand ${ }^{\text {a, c }}$, Jeffrey Ladderud ${ }^{\text {b, d }}$, Ilsu Lee ${ }^{\text {, }}$, \\ Lee Landkamer ${ }^{a}$, Linda Figueroa ${ }^{a}$, Jonathan O. Sharp ${ }^{\mathrm{a}, \mathrm{b}, *}$ \\ a Colorado School of Mines, Department of Civil and Environmental Engineering, 1500 Illinois St., Golden, CO 80401, USA \\ ${ }^{\mathrm{b}}$ Colorado School of Mines, Hydrologic Science and Engineering Program, 1500 Illinois St., Golden, CO 80401, USA \\ c Swedish University of Agricultural Sciences, Department of Forest Mycology and Plant Pathology, Box 7026, 75007 Uppsala, Sweden \\ ${ }^{\mathrm{d}}$ Freeport McMoRan Inc., 1600 Hanley Blvd., Oro Valley, AZ 85737, USA
}

\section{A R T I C L E I N F O}

\section{Article history:}

Received 26 October 2016

Received in revised form

17 February 2017

Accepted 17 February 2017

Available online 20 February 2017

\section{Keywords:}

Sulfate-reducing bacteria

Zinc-sulfide

Spatial distribution

Microbial diversity

Bioimmobilization

Mining influenced water

\begin{abstract}
A B S T R A C T
Sulfate-reducing bioreactors (SRBRs) represent a passive, sustainable, and long-term option for mitigating mining influenced water (MIW) during release. Here we investigate spatial zinc precipitation profiles as influenced by substrate differentiation, inorganic ligand availability (inorganic carbon and sulfide), and microbial community structure in pilot-scale SRBR columns fed with sulfate and zinc-rich MIW. Through a combination of aqueous sampling, geochemical digests, electron microscopy and energy-dispersive x-ray spectroscopy, we were able to delineate zones of enhanced zinc removal, identify precipitates of varying stability, and discern the temporal and spatial evolution of zinc, sulfur, and calcium associations. These geochemical insights revealed spatially variable immobilization regimes between SRBR columns that could be further contrasted as a function of labile (alfalfa-dominated) versus recalcitrant (woodchip-dominated) solid-phase substrate content. Both column subsets exhibited initial zinc removal as carbonates; however precipitation in association with labile substrates was more pronounced and dominated by metal-sulfide formation in the upper portions of the down flow columns with micrographs visually suggestive of sphalerite $(\mathrm{ZnS})$. In contrast, a more diffuse and lower mass of zinc precipitation in the presence of gypsum-like precipitates occurred within the more recalcitrant column systems. While removal and sulfide-associated precipitation were spatially variable, whole bacterial community structure (ANOSIM) and diversity estimates were comparatively homogeneous. However, two phyla exhibited a potentially selective relationship with a significant positive correlation between the ratio of Firmicutes to Bacteroidetes and sulfide-bound zinc. Collectively these biogeochemical insights indicate that depths of maximal zinc sulfide precipitation are temporally dynamic, influenced by substrate composition and broaden our understanding of bio-immobilized zinc species, microbial interactions and potential operational and monitoring tools in these types of passive bioreactors.
\end{abstract}

() 2017 Elsevier Ltd. All rights reserved.
Abbreviations: MIW, Mining Influenced Water; SRBR, Sulfate-Reducing Bioreactor; SB, Sulfide-Bound; AEC, Absorbed/Exchangeable/Carbonate-Bound; ICP-AES, Inductively coupled plasma atomic emission spectroscopy; FESEM, Field-Emission Scanning electron microscopy; SEM-EDX, Scanning electron microscopy with energy dispersive X-ray spectroscopy; ANOSIM, ANalysis Of SIMilarity; SA, sawdust and alfalfa; WA, woodchips and alfalfa; A, alfalfa; WSA, woodchips, sawdust and alfalfa; S, sawdust; SW, sawdust and woodchips; W, woodchips.

* Corresponding author. Colorado School of Mines, Department of Civil and Environmental Engineering, 1500 Illinois St., Golden, CO 80401, USA.

E-mail address: jsharp@mines.edu (J.O. Sharp).

1 Current address: CDM Smith, 14432 SE Eastgate Way \# 100, Bellevue, WA 98007, USA.

\section{Introduction}

The release of mining influenced waters (MIW) containing toxic metal(loid)s from current and legacy mining operations presents challenges toward human health and wellbeing, the ecology of receiving waters, and economic prosperity (Méndez-García et al., 2014). Alarmingly, remediation costs have been estimated at $\$ 35$ billion for the approximately 500,000 orphaned and abandoned mines present throughout the United States with similar challenges globally (United States Environmental Protection Agency, 2000). 
Mitigation strategies need to be designed and managed for these non-operational sites that generate MIW for extended timeframes while taking into consideration costs associated with sites where economically responsible parties may not be identified (Sheoran and Sheoran, 2006). MIW chemistry is highly variable, and while here we specifically address zinc contamination, a number of metals and variety of conditions can prevail (Plumlee et al., 1999). Passive sulfate-reducing bioreactors (SRBRs) are a promising mitigation strategy for remote, orphaned sites as a low maintenance and long-term means to ameliorate metal toxicity associated with points of MIW release. In addition to their environmental remediation applications, these systems provide an environmentally relevant operational venue to investigate dynamic metal precipitation in association with anoxic microbial respiratory processes under reducing conditions.

Lignocellulose-based SRBRs have been investigated previously with respect to performance in mining impacted waters contaminated with iron, manganese, cadmium, nickel, and zinc (Neculita et al., 2007). However, limited understanding of spatial biogeochemical patterns in these engineered systems and their relevance to design and operation have implications upon their longevity, cost, and broader implementation. Abiotic factors that can affect metal immobilization in SRBRs include $\mathrm{pH}$, dissolved oxygen, temperature, carbon release and bioavailability, and MIW composition (Concas et al., 2006). In addition to water chemistry parameters, it has been shown that the recalcitrance of solid-phase organic substrates is a strong selective driver of resident microbial communities (Drennan et al., 2016). In these systems, metal sulfide precipitation results from syntrophic relationships between fermentative organisms and sulfate-reducing bacteria (SRB). The former mediate the process of anoxic cellulose and lignin degradation to simple organic molecules, such as lactate, which in turn are oxidized by the SRB (Drennan et al., 2016; Liamleam and Annachhatre, 2007).

In unmanaged terrestrial environments, microbial community structure has been shown to exhibit increasing dissimilarity with physical distances measured in meters suggesting locally interrelated microbial biogeography (King et al., 2010). Similarly, microscale functional stratification in biofilms has been demonstrated by municipal wastewater treatment reactors (Almstrand et al., 2013, 2014; Schramm et al., 1999) to delineate physiological and functional differences of phylogentically similar guilds. However, there has been comparatively little research done on spatial biogeochemical patterns in SRBRs. After oxygen is consumed, redox stratification in SRBRs, as with analogous reducing systems, is strongly influenced by the terminal electron accepting process (TEAP). When a single electron acceptor is in excess, such as sulfate, in combination with an abundance of spatially homogenous electron donors through the fermentative release of species such as lactate from plant detritus, the system is not poised for vertical redox stratification (Drennan et al., 2016; McGuire et al., 2000). Under these conditions prevailing binding efficiencies and the availability of aqueous metals to organic and inorganic ligands may have a greater bearing on spatial and temporal metal(loid) precipitation than localized bacterial community structure.

A conceptual model of the temporal evolution of geochemically relevant variables in SRBRs is presented in Fig. 1 and was used to inform our operational understanding of this experimental system. The initiation of zinc and sulfate removal due to $\mathrm{ZnCO}_{3}$ and $\mathrm{CaSO}_{4}$ precipitation, as a result of limestone dissolution, could occur in shallow regions of the SRBR and/or early in operation followed by further zinc removal at the onset of biogenic sulfide production. Furthermore the maturation of substrate is predicted to coincide with increased evolution of biogenic sulfide and consequently complete zinc removal. Our current work builds upon these themes

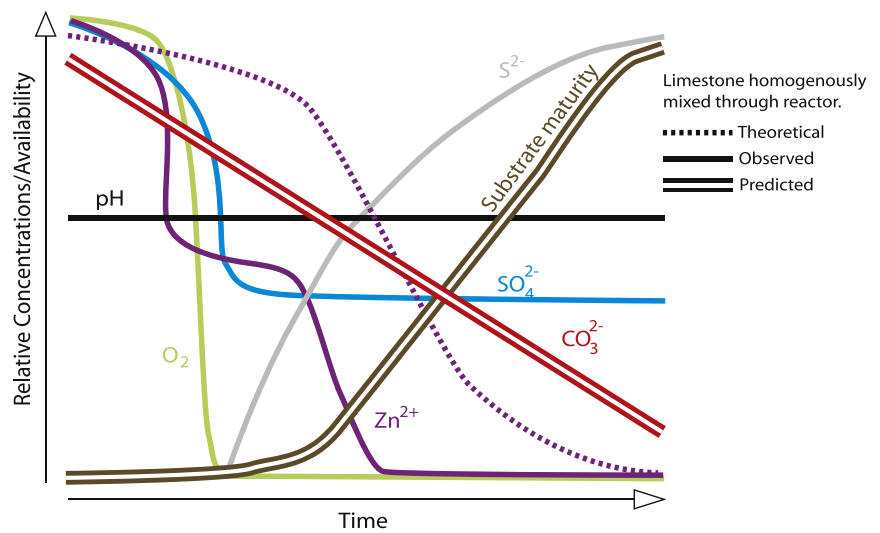

Fig. 1. SRBR conceptual model where theoretical concentrations or availabilities are represented by dotted lines, observations made in these systems are in single lines, and predictions are in double lines. This conceptual model highlights the role of limestone dissolution, carbonate release (red) and subsequent $\mathrm{ZnCO}_{3}$ formation as an initial removal mechanism. This is in contrast with a scenario where sulfide is the sole inorganic ligand available for zinc to complex with (dotted purple line). Futhermore this conceptual model highlights decreases in carbonate reactivity with time (Miller et al., 2011 and Miller et al., 2013). The predicted increase in substrate maturity (brown) coincides with an increase in sulfide evolution (grey) and complete zinc removal (purple). (For interpretation of the references to colour in this figure legend, the reader is referred to the web version of this article.)

by presenting a scenario in which determinant electron acceptors and donors supporting microbial respiration, in this case sulfate and organic carbon, are not spatially limiting as would be more typically observed in organic-rich aquifer sediments (Bekins et al., 1999). Furthermore, sulfate is often much higher in MIW than in aquifer sediments and therefore less likely to become exhausted (Moore and Luoma, 1990). Within our designed SRBR, organic substrates comprised of varying ratios of woodchips, alfalfa, and sawdust are fermented to fatty acids such as lactate and acetate over large spatial regions within the vertical bioreactor system (Liamleam and Annachhatre, 2007).

The present study adds to biogeochemical insights in SRBRs by contrasting solid-phase carbon sources and degradability as a variable to investigate the spatial progression of abiotic precipitate formation and microbially-mediated sulfide evolution to develop indicators of this process. To our knowledge, this is the first SRBR study addressing geochemical stratification as it relates to spatial microbial colonization. Within this framework, we hypothesized that SRBRs with a spatially homogeneous microbial community would, assuming optimal loading conditions, yield similarly homogeneous zinc-sulfide precipitation. This was tested by comparing spatial zinc precipitation in systems containing organic substrate of variable recalcitrance to whole community structure, diversity, and phylogeny. This study aims to illuminate spatial and temporal feedback of precipitate formation in response to substrate selection, where the community structure is comparatively static due to substrate availability, in order to better inform how design and operational parameters can be optimized for passive SRBRs.

\section{Methods}

\subsection{Column array}

Specifics of column construction and design are detailed in Drennan et al., 2017. Experimental details related to inoculation, flow regimes, sampling, and mass loading are provided in (Drennan et al., 2016), which investigated syntrophic microbial associations 
in these columns as a function of substrate variables. In brief, the array consisted of seven $20 \mathrm{~L}$ down-flow lignocelluloses-based sulfate-reducing PVC columns ( $132 \mathrm{~cm}$ by $15.25 \mathrm{~cm}$ ID) with liquid and solid sampling ports proximal to the upper $(30.5 \mathrm{~cm}$ from the top), middle $(71 \mathrm{~cm})$, and lower $(106 \mathrm{~cm})$ regions of the columns. Columns contained varying permutations of alfalfa hay, sawdust, and woodchips, denoted as follows: WSA (50\% woodchips, 10\% sawdust, and 10\% alfalfa hay), SA (35\% sawdust and 35\% alfalfa hay), WA (35\% woodchips and 35\% alfalfa), A (70\% alfalfa hay), WS (35\% woodchips and 35\% sawdust), S (70\% sawdust), and W (70\% woodchips). A constant percentage of limestone (30\% w/w) was homogeneously mixed throughout all reactors. The residence time of the columns was on the order of weeks but varied with substrate. While turbulence equilibrium associated complications cannot be fully dismissed, flow rates were modest and microbial ecology indicators were previously demonstrated to exhibited little discernible response to flow perturbations (Drennan et al., 2016). Columns were operated for more than 500 days with average sulfate influent concentrations of $5339 \pm 95 \mathrm{mg} / \mathrm{L}$ and effluent in excess of $2000 \mathrm{mg} / \mathrm{L}$. Sulfide was initially detected in columns dominated with alfalfa at day 150 or approximately 3 pore volumes. Liquid samples were collected from the upper, middle, and lower ports, adjacent to the solid ports, shortly after this initial detection of sulfide in the effluent to determine regions of enhanced zinc removal. Effluent continued to be sampled at approximately weekly intervals for the duration of the experiment. Subsequent sampling campaigns on days 345 and 494 involved collection of solid substrate and liquid collection from these spatially defined ports.

\subsection{Chemical analysis of liquid and solid-phase samples}

To determine the metal composition of the liquid phase in the column, $10 \mathrm{~mL}$ aqueous samples were collected from each sampling port of each column, from the upper region downward, on days 107 , 345 , and 494 of operation. Reported zinc removal rates between sampling ports was calculated by subtracting the zinc concentration at a given port from the zinc concentration at the port immediately above, multiplying by flow rate. In the case of the upper region, zinc concentrations were subtracted from the influent concentration. Negative values indicate a net release of zinc as quantified by effluent concentrations higher than influent. Aqueous sampling was conducted immediately prior to retrieval of solid samples to minimize potential disruptions such as particulate suspension caused by the substrate sampling process. Aqueous samples were acidified (final $\mathrm{pH}<2$ ) with concentrated $(70 \%)$ reagent grade nitric acid on site, and filtered within $48 \mathrm{~h}$ of collection. Metal concentrations were measured using inductively coupled plasma atomic emission spectroscopy (ICP-AES).

To query immobilized metal associations, one-gram (dry weight) aliquots of column substrate (collected on day 494) from each sampling port were dried anoxically in an anaerobic chamber containing 95\%:5\% $\mathrm{N}_{2}: \mathrm{H}_{2}$. A sequential extraction procedure (Carlsson et al., 2002) was modified in order to distinguish between the adsorbed/exchangeable/carbonate (AEC) fraction and the sulfide-bound (SB) fraction of metals. In brief this protocol modification included using $20 \mathrm{~mL}$ rather than $10 \mathrm{~mL}$ of $1 \mathrm{M} \mathrm{CH}_{3} \mathrm{COONa}$ (pH 5.0) and rinsing with $10 \mathrm{~mL}$ of de-ionized water rather than the prescribed $5 \mathrm{~mL}$ for extraction of AEC fractions. SB extraction was performed as presented in extraction "E" in (Carlsson et al., 2002) using $750 \mathrm{mg} \mathrm{KClO} 3$ and $5 \mathrm{~mL}$ of $12 \mathrm{M} \mathrm{HCl}, 5 \mathrm{~mL} 4 \mathrm{M} \mathrm{HNO}_{3}$ and a $90{ }^{\circ} \mathrm{C}$ water bath.

\subsection{Scanning electron microscopy (SEM) and energy-dispersive $X$ - ray spectroscopy (EDX)}

In order to obtain micrographs of representative precipitates, anoxically dried samples were sputtered with gold (Hummer IV Sputtering system) and examined with a JEOL JSM-700F FieldEmission SEM with a Schottky type field-emission gun for an electron source. Anoxically dried, archived samples were also subjected to electron microscopy and elemental analysis employing a Hitachi TM 1000 SEM (Hitachi Ltd., Tokyo, Japan) system equipped with a Quantax 50 EDX system. Samples were distributed onto adhesive carbon tape and EDX spectra were acquired at randomly selected positions following standard procedures for biovolume fraction quantification as adapted from digital image analysis in microbial ecology (Almstrand et al., 2013). Running averages $(\mathrm{n}=30)$ were calculated for the normalized atomic mass percent of zinc, sulfur, and calcium (Figs. S1A\&B) (specific mineralogy could not be determined by this method). Elements other than zinc, calcium, and sulfur (i.e. carbon and oxygen) were not included in the analysis. Analysis of the WS lower sample from day 494 was not performed due to loss of substrate in the SEM vacuum.

\subsection{Bioinformatics and statistical analyses}

Column sampling, nucleic acid extraction, and sequence analysis for SRBR columns have been described previously (Drennan et al., 2016). In brief, phenol-chloroform DNA extraction was adapted from (Zhou et al., 1996). Sequence analysis was performed using Quantitative Insights Into Microbial Ecology (QIIME) version 1.8.0 and sequences were aligned to the Greengenes reference sequence using PyNAST (Caporaso et al., 2010). To determine if community structure differed spatially within and between substrates the ANOSIM (ANalysis Of SIMilarity) test (Chapman and Underwood, 1999) (compare_categories.py) generated $R$ test statistics and $p$ values from 999 permutations of bootstrapped sequences. Shannon and Chao1 indices were calculated, after rarefying to 6300 sequences, to quantify spatial and zinc-associated removal trends in evenness and richness respectively. After rarefaction, samples A-upper region, WS-middle, WA-middle, SA-upper and lower regions were omitted for diversity indices calculations as they had less than 6300 sequences. Significance was assigned for p-values less than or equal to 0.05 . Sequences have been submitted to MGRAST under ID 4629386.3.

\section{Results \& discussion}

\subsection{Aqueous removal}

Diverse metal precipitates with various stabilities have been shown to form in SRBRs including carbonates, (oxy)hydroxides, sulfides, and adsorption to organic matter (Neculita et al., 2008, 2007). In order to query zinc removal patterns, implications for stability, and formation mechanisms for resultant precipitates, aqueous and solid-phase samples were analyzed in concert within these spatially and temporally stratified systems. Operational similarities identified previously (Drennan et al., 2016) rationalized the grouping of columns for statistical trends based on overall performance, where those with $>10 \%$ alfalfa (SA/WA/A) were designated as containing a more labile solid-phase organic substrate. This was contrasted with those containing comparatively recalcitrant ligneous materials (WS/S/W).

The zinc concentration in the introduced mine water was $151 \pm 7 \mathrm{mg} / \mathrm{L}$ over the course of the 494 day experiment. After 107 days (Table 1 ), zinc removal in columns SA/WA/A and WS/S/W were not significantly different ( $44 \pm 5$ and $44 \pm 7 \mathrm{mg} / \mathrm{d}$ respectively). 
Table 1

Aqueous zinc removal ( $\mathrm{mg}$ /day) for the indicated reactive volume after 107, 345 and 494 days of operation of substrate permutation columns. Darker green indicates regions of enhanced removal and yellow indicates regions of less removal.

\begin{tabular}{cccccccc}
\multicolumn{7}{c}{$\mathrm{mg} /$ day zincremoved for a given reactive volume } \\
\hline 107 days & SA & WA & A & WSA & WS & S & W \\
\hline Upper & -2 & -8 & -3 & 3 & -5 & 0 & 36 \\
Middle & 46 & 34 & 46 & 22 & 35 & 52 & 2 \\
Lower & 3 & 20 & -5 & 3 & 13 & 0 & 0 \\
TOTAL & 47 & 46 & 38 & 28 & 42 & 51 & 38 \\
\hline 345 days & SA & WA & A & WSA & WS & S & W \\
\hline Upper & 124 & 75 & 39 & 8 & 1 & 6 & 0 \\
Middle & -1 & 58 & 93 & -2 & 4 & -4 & 2 \\
Lower & 10 & 1 & 1 & 0 & 0 & 1 & 0 \\
TOTAL & 133 & 133 & 134 & 7 & 5 & 4 & 2 \\
\hline 494 days & SA & WA & A & WSA & WS & S & W \\
\hline Upper & 2 & -41 & -112 & 75 & 59 & 12 & -4 \\
Middle & 38 & 124 & 293 & 51 & 3 & 37 & 9 \\
Lower & 149 & 154 & 72 & 0 & -2 & -21 & 1 \\
TOTAL & 189 & 237 & 252 & 126 & 61 & 28 & 5 \\
\hline
\end{tabular}

This modest, but measurable removal as explored later in the manuscript could in part be attributed to the formation of $\mathrm{ZnCO}_{3}$ that would primarily form independently of biological activity during limestone dissolution (Landkamer et al., 2013). By 345 days of operation, the labile and recalcitrant carbon sources had clearly diverged with respect to aqueous zinc removal. Columns containing greater than $10 \%$ alfalfa $(\mathrm{SA} / \mathrm{WA} / \mathrm{A})$ removed $133 \pm 0.7 \mathrm{mg} /$ $\mathrm{d}(>90 \%)$ of influent zinc compared to a reduced capacity of $3.7 \pm 1.7 \mathrm{mg} / \mathrm{d}(\sim 2.5 \%)$ in ligneous columns (WS/S/W). As conceptualized in Fig. 1, a reduced rate of limestone dissolution would limit the precipitation of zinc carbonate (Miller et al., 2013, 2011) and provide an explanation for overall decreases in zinc removal by $\mathrm{ZnCO}_{3}$ formation. While similar degrees of decreasing limestone reactivity presumably occurred in all columns, the net effect on removal was more apparent in the ligneous columns due to limited organic substrate bioavailability and in turn sulfide production. Over the subsequent 149 days, zinc removal became more pronounced in columns WS/S/W but not to the same extent as was observed in columns SA/WA/A.

Regardless of substrate, zinc removal initiated in the upper to middle reaches of the down flow reactors (Table 1 ). While our temporal resolution limits interpretation, aqueous removal profiles revealed a downward progression of the zinc removal front in columns with more labile substrates. Specifically, the zone of most pronounced zinc removal in columns SA/WA/A migrated from the upper region at 345 days to middle and lower reaches of the columns after 494 days. This transition could be the result of increased sulfide evolution between time points (Drennan et al., 2016). That is, initial removal may be predominately attributable to abiotic $\mathrm{ZnCO}_{3}$ formation whereas after 345 days there was prodigious biogenic sulfide evolution facilitating removal as zinc-sulfide. At this point, columns SA/WA/A removed comparatively little zinc ( 10 , $1, \& 1 \mathrm{mg} / \mathrm{d}$ respectively) in the lower regions at 345 days presumably due to depletion of aqueous zinc. This depletion suggests that columns SA/WA/A could have managed mitigation at a higher zinc-loading rate. After 494 days, zinc removal migrated downward toward the middle and lower regions of the columns (Table 1). Interestingly, the upper regions of columns WA and A appeared to be releasing zinc ( -41 and $-112 \mathrm{mg} / \mathrm{d}$ respectively) (Table 1 ), which could result from dissolution of less stable precipitates such as zinc carbonates (Landkamer et al., 2013) or potential perturbations associated with sampling.

Apart from the difference in overall performance, zinc removal fronts associated with labile and recalcitrant organic substrates also exhibited different migration patterns. Zinc removal in columns $\mathrm{WS} / \mathrm{S} / \mathrm{W}$ was limited throughout the experiment. After 494 days there was some moderate zinc removal initiating in the upper regions of these columns (Table 1) that mimicked the more active zones at earlier time points in alfalfa containing columns. The nature of these precipitates is explored later in this paper. However, contrary to what was observed in labile SRBRs, columns WS/S/W exhibited no perceptible migration of aqueous zinc removal in 494 days. Column WSA bridged the labile and recalcitrant column subsets in terms of performance and substrate composition. This transitional column, which contained $10 \%$ alfalfa, exhibited limited zinc removal after 345 days when other higher alfalfa-content columns were removing $>90 \%$ of introduced zinc (Table 1 ). However, 494 days into the experiment, WSA underwent a performance transition corresponding to $>90 \%$ zinc removal that initiated in the upper region of WSA (Table 1). This reflected the regional trend of increased performance initially observed in the upper reaches of the other columns.

\subsection{Precipitate formation mechanisms}

Aqueous measurements represent selected snapshots over a 494 day operational period and provide insights into spatial processes but are limited in their ability to confirm mechanisms of immobilization. To investigate stability and precipitate form (i.e. sulfide vs. carbonate precipitates) we queried specific precipitation mechanisms through sequential extractions. The extractions were conducted on sacrificial substrates harvested at the end of the experiment, thus representing a culmination of processes over the course of 494 days of column operation. Considering the limestone content of these systems and chemical equilibrium predictions, it is possible that some of the immobilization behavior could be explained by the abiotic precipitation of zinc carbonates (Fig. 1). In addition to different mechanisms of immobilization, carbonatebound precipitates have different stabilities and therefore implications for re-mobilization when contrasted with sulfide-bound forms (Morel et al., 1993). The extraction digests provided differentiation between precipitates and revealed spatial trends corresponding to the efficacy of the columns.

Sulfide-bound (SB) zinc resulting as a product of microbial sulfate reduction varied significantly between treatments. Solid-phase substrates harvested from SA/WA/A columns had significantly more $S B$ zinc $(70 \pm 38 \mathrm{mg} / \mathrm{g}$ of substrate) than substrates harvested in $\mathrm{WS} / \mathrm{S} / \mathrm{W}$ columns $(7 \pm 4 \mathrm{mg} / \mathrm{g}$ of substrate) at all depths (Table S1). In contrast, all columns had similar quantities of adsorbed/exchangeable/carbonate (AEC)-bound zinc (7.7 \pm 8.7 and $6.4 \pm 3.3 \mathrm{mg} / \mathrm{g}$ respectively for SA/WA/A and WS/S/W respectively) with no discernible depth trend. The similarity can be explained by the homogenous mixing of limestone throughout all of the solid phase matrices as a pH buffering and alkalinity agent.

Spatial trends in sulfide-bound zinc fractions formed in association with biological activity were generally consistent with aqueous zinc removal results, where the majority of sulfide-bound zinc accumulated in the upper reaches of the labile columns $(\mathrm{P}=0.05$, T-test) (Fig. 2). This accumulation of SB zinc in the upper portions of the columns in conjunction with removal data (Table 1), further supports that zinc was depleted from the water before reaching the lower regions and that the capacity for zinc removal is higher than observed, especially so in the columns with the more labile substrates. The higher concentrations of SB zinc and the observed aqueous zinc concentrations in the upper reaches of columns SA/WA/A indicate that certain zones were actively precipitating and accumulating SB zinc throughout the experiment and SB zinc was continuously accumulating in these regions, accounting for the enrichment in the upper portions. While limited to 


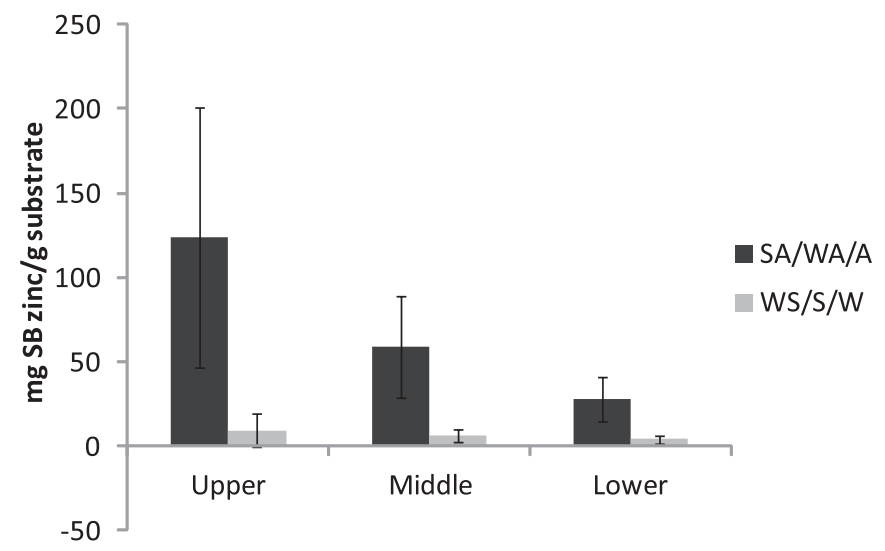

Fig. 2. Spatial Digest Results Substrate digests reveal a pronounced depth profile for sulfide-bound zinc in columns SA/WA/A, an analogous pattern was not observed for $\mathrm{WS} / \mathrm{S} / \mathrm{W}$ columns.

the final time point, the depth profile of SB zinc in columns SA/WA/ A (Fig. 2, Table S1) was consistent with the progression of a zinc removal front migrating down the columns later in the experiment (Table 1). That is, SB zinc had less time to accumulate in the middle and lower portions, and was therefore comparatively enriched in the upper regions.

The mass of sulfide-bound zinc was positively correlated with the mass of alfalfa $(P=0.002)$ and negatively correlated with woodchip mass (Spearman; $\mathrm{P}=0.0002$ ). Sulfide bound zinc was not significantly higher in column WSA than in other recalcitrant columns (Table S1), which could be explained by limited accumulation associated with the comparatively late onset of zinc removal (Table 1). A possible outcome is that WSA would accumulate significantly more SB zinc than columns devoid of alfalfa if the experiment continued past 500 days. Indeed WSA exhibited a similar SB trend with depth as other labile columns (Table S1). This suggests that there may be a benefit to employing a combination of labile substrates to catalyze early sulfide generation and complementarily, more recalcitrant carbon sources for sustained carbon release.

\subsection{Elemental associations and visual analysis of precipitates}

To further inform the mechanisms and fate of zinc immobilization, solid-phase substrates harvested from different depths during column operation were visualized on a field emission scanning electron microscope (FESEM) and analyzed for elemental associations using comparative energy dispersive X-ray spectroscopy (EDX) analysis. Visualization of representative precipitates by FESEM revealed an abundance of spherical zinc-containing spheres in columns SA/WA/A, that were visually analogous to biogenic sphalerite $(\mathrm{ZnS})$ deposits from SRB-dominated biofilms (Labrenz, 2000), (Fig. 3A). These sphalerite-like precipitates were distinct from those observed in substrates harvested from columns WS/S/W where $\mathrm{Zn}$-containing precipitates eluded our visual analysis. Rather, those columns contained a stronger presence of precipitates where calcium was associated with sulfur and were visually consistent with $\mathrm{CaSO}_{4}$ (gypsum) morphology (Hamarneh, 2015) (Fig. 3B).

Quantification of associations between immobilized zinc, sulfur, and calcium was achieved through randomly collecting 30 spectra from each harvested sample and calculating a running average of the atomic mass percent of the elements of interest (Fig. S1 A\&B). To focus this analysis on relative associations and remove interferences present from the organic substrates, atomic mass percents of the three elements were normalized to $100 \%$ followed by graphical interpretation of trends and associations using ternary plots (Fig. 4A-C) and relative proportions on bar charts (Fig. S2). The employed EDX was sensitive to the general character and evolution of precipitates in each column; however, limitations included an inability to determine specific mineralogy from the elemental composition or differentiate between organic and inorganic carbon. As a result, we were unable to directly explore or distinguish elemental associations with carbonate such as the $\mathrm{ZnCO}_{3}$ precipitates inferred from modeling efforts (Landkamer et al., 2013), extractions and FESEM (Fig. 3B). The low mass percent of these precipitates relative to substrate further limited our ability to employ X-ray diffraction to determine definitive mineralogy.

Consistent with efficient aqueous zinc removal (Table 1 ) and significant SB zinc formation (Figs. 2 and 3), samples collected from columns containing high alfalfa content generally exhibited higher relative proportions of zinc than woody columns at 345 days (Fig. 4A and C, Fig. S2, and Table S2). Spatial precipitation evolved over the next 149 days, where the zinc-sulfide immobilization front migrated down in columns SA/A/WA so that zinc and sulfur ratios were generally similar across depths within the columns suggesting that sulfide precipitation was the primary immobilization mechanism throughout these systems (Fig 4C, Fig. S2, and Table S2). While these ratios began to converge, digests revealed that the majority of the SB zinc mass was associated with the upper reactive material of these columns (Fig. 2). This preferential accumulation of $\mathrm{SB}$ zinc within the upper reactive volume is to be expected in a scenario where introduced zinc was depleted prior to reaching the
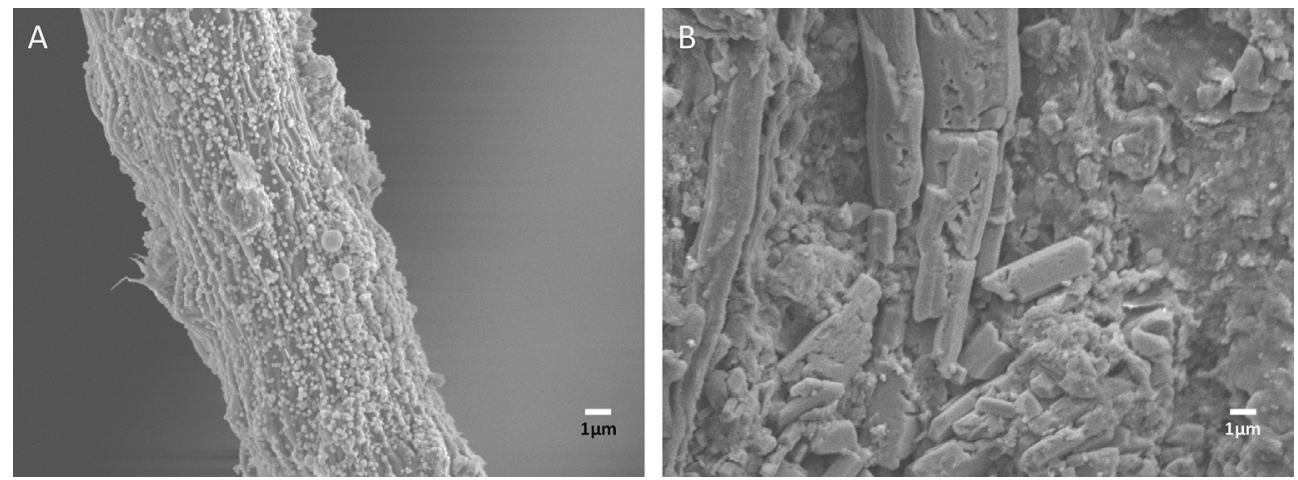

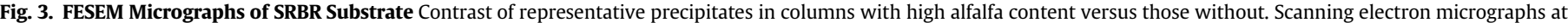

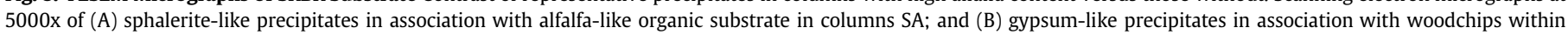
column W. 


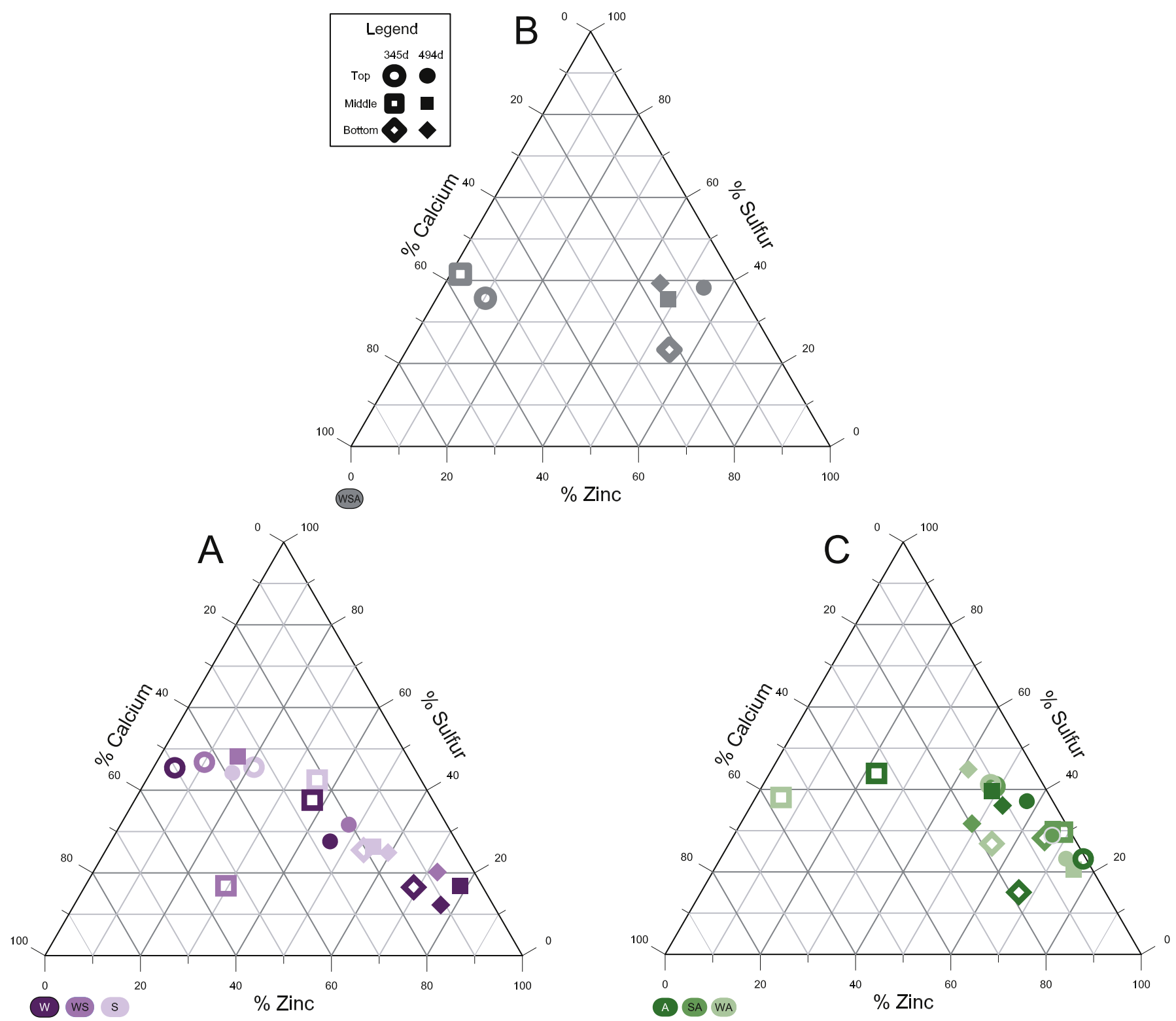

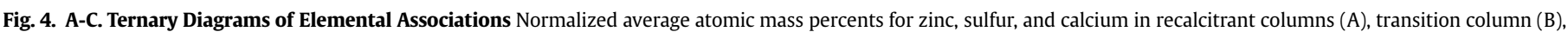
and labile columns (C). Running averages and 95\% confidence intervals are provided in Table S3.1.

lower portions of these columns (Table 1). Furthermore, at the neutral pHs encountered within these systems, nearly one half of the biogenically produced sulfide would exist as gaseous $\mathrm{H}_{2} \mathrm{~S}$ and presumably propagate upward within the reactor (Steyermark, 1966).

While the aqueous zinc removal (Table 1) and insights from our different solid-phase analyses were congruent with respect to overarching trends, specific discrepancies can be attributed to the snapshot nature of the liquid analysis as opposed to the accumulative nature of precipitation observed in extraction results and SEM-EDX observations. This is apparent in columns SA/WA/A, but especially so in column SA where aqueous data (Table 1) revealed enhanced removal in the upper portion at 345 days with a transition to more removal in the middle and lower regions by 494 days.

Woody-based column zinc-precipitation patterns were distinct from those observed in alfalfa columns as they exhibited a comparatively late onset of zinc removal and an initiation of higher zinc deposition in the lower reaches of the columns that migrated upward with time (Fig. 4A). Possible explanations include that woodchips lack the surface area of alfalfa and sawdust, the potential need to overcome initial inhibitory effects of antimicrobial terpenes present in pinewood (Himejima et al., 1992), and increased bioavailability of solid-phase substrates with time. Observations from 345 days revealed a dominance of Ca-S type precipitates (presumably calcium sulfate) in the tops of these columns, and limited instances of $\mathrm{Zn}-\mathrm{S}$ type precipitates in the middle and lower reaches (Fig. 4, Fig. S2 and Table S2). The elemental deposition in WS/S/W evolved over the subsequent half year where after 494 days, the presence of $\mathrm{Zn}-\mathrm{S}$ in the upper regions of the columns increased but not to the extent of that in the lower portions of the columns (Fig. 4, Fig. S2 and Table S2). This late onset of zinc deposition aligns with the lack of a significant spatial trend for SB zinc in columns WS/S/W (Fig. 2). The lack of SB zinc (Table S1) and limited $\mathrm{Zn}-\mathrm{S}$ associations in the upper reactive volumes of columns WS/S/W after 345 days (Fig. 4C, and Fig. S2) indicates that aqueous zinc removal observed early in the experiment (Table 1) was 
attributable to alternative removal mechanisms such as $\mathrm{ZnCO}_{3}$ formation (Landkamer et al., 2013). After 494 days the recalcitrant carbon columns reflected similar initial elemental associations to those observed in alfalfa-based columns after 345 days.

The performance transition observed in column WSA (Table 1) was especially apparent in the SEM-EDX data (Fig. 4B). Similar to other woody columns, zinc-sulfur association in column WSA appeared more pronounced in the lower portion of the column. This is not consistent with removal and digest data, which suggest removal (Table 1) and precipitation (Table S1) initiated in the upper part of WSA similar to the higher percent content alfalfa systems. Elemental associations were starkly different over the 150-day evolution between time points. While the upper and middle portions of column WSA revealed a strong Ca-S signature at 345 days, with the lower portion exhibiting a stronger $\mathrm{Zn}-\mathrm{S}$ signature, 149 days later all depths were decidedly Zn-S dominated (Fig. 4B). It is plausible that were the experiment to continue past 500 days, further zinc and sulfur would have time to accumulate in the lower regions and, WSA would have a higher mass of SB zinc in the middle and lower regions. As discussed in prior sections, column WSA's performance transition initiated in the lower reactive volume, which is congruent to observations made for WS/S/W where zinc and sulfur deposition also begins in the middle and lower reactive volumes (Fig. 4A). It is difficult to attribute the transition from primarily $\mathrm{Ca}-\mathrm{S}$ deposition to $\mathrm{Zn}-\mathrm{S}$ deposition to a single factor, but maturation of the recalcitrant fraction of the reactive substrate is a likely explanation (Drennan et al., 2016).

Interestingly, given depth and time, the reactors containing recalcitrant carbon sources began to exhibit similar elemental deposition as reactors containing labile carbon sources (Table 1 , Fig. 4, Fig. S2, and Table S2), albeit at a much lower rate of accumulation. The determination of removal rates and precipitate characterization is seminal to monitoring performance and optimizing loading rates. The establishment of zinc removal in the upper reaches of columns containing more labile carbon sources suggests that loading could be increased for enhanced removal efficiency. Furthermore, temporal trends from the transitional column WSA suggest that a blend of organic substrate recalcitrance could effectively extend the operational effectiveness of these columns by delaying a downward migration of the zinc-sulfide front. From an engineering perspective, in reactors such as these that are not carbon or sulfate limited, the solid phase organic matrix is a stronger selective driver than depth, and in turn determinative of performance and appropriate residence times for optimal removal.

\subsection{Ecological distribution of bacteria}

Prior investigation of lignocellulosic SRBR communities demonstrated that solid-phase substrates impart ecological variations in symbiotic bacterial associations with fermentation and the subsequent consumption of released fatty acids (Drennan et al., 2016). To query for potential depth-driven ecological trends in association with zinc immobilization, we first investigated broader trends in community structure for alfalfa rich systems versus those devoid of this substrate. With respect to overall microbial diversity, columns SA/WA/A and WS/S/W yielded similar Shannon and Chao1 estimates at both time points (Table S4). Importantly, neither Chao1 nor Shannon trended with depth (Table S4) or rates of mass zinc removal $\left(\mathrm{R}^{2}=0.003\right.$ and 0.009 respectively). ANalysis Of SIMilarity (ANOSIM) (Chapman and Underwood, 1999) tests revealed that neither of the communities in SA/WA/A $(R=-0.04$; $\mathrm{p}$-value $=0.01)$ nor $\mathrm{WS} / \mathrm{S} / \mathrm{W}(\mathrm{R}=-0.2$; p-value $=0.01)$ varied with depth. While negative ANOSIM $R$ values such as these have previously been ignored as sampling error (Clarke and Warwick, 1994), it is also suggested that negative $\mathrm{R}$ values imply non-independent samples
(Chapman and Underwood, 1999). Broader ecological inquiry into analogous regimes including leaf degradation, intestine microbiology, and wastewater treatment has revealed that exploration of the source of bacterial diversity can reconcile how analogous biogeochemical systems vary spatially and temporally, while harboring a homogenous microbial community (Curtis and Sloan, 2004).

SRBRs are known to develop microbial biofilms (Mohan et al., 2005) that may act as a source of bacterial colonization in connected regions (Davey and O'Toole, 2000). Homogeneously distributed biofilms in conjunction with a constant release of electron donors from the lignocelluloses-based substrates and excess of sulfate helps to explain the lack of spatial community heterogeneity at the pilot-scale addressed here. The biogeochemical regime at the top of a down-flow system can influence the deeper reaches, elucidating the source of vertical nonindependence in microbial communities, as indicated by negative RANOSIM values. Similarly, the overall community structure did not vary temporally within each column when contrasting harvested materials between 345 and 494 days of operation revealing a stable, resilient community regardless of flow shifts, metal loading regimes and a subsequent inoculation event (Drennan et al., 2016).

Despite the lack of spatial whole community variability or trends in diversity indices, further insights from phylogenetic analysis could be found when focusing on the phyla Firmicutes and Bacteroidetes and taxonomic tiers within (Fig. 5), which collectively accounted for $62 \pm 4 \%$ of the total bacterial populations. Spatial trends revealed increasing ratios of Firmicutes to Bacteroidetes in zones of active zinc sulfide immobilization independent of substrate. For example, the relative abundance ratio of Firmicutes to Bacteroidetes increased with depth within columns WS/S/W $\left(\mathrm{R}^{2}=0.9\right)$. This was reflected in an increase in the relative abundance of Ruminococcus sp. (Firmicutes) and a decrease in Dysgonomonas sp. (Bacteroidetes) (Fig. 5). Firmicutes and Bacteroidetes are phyla with diverse functions attributed as indicator clades in both human gut microbiota (Ley et al., 2006) and in anaerobic digesters (Chen et al., 2016). Regardless of time, depth, or substrate the phylum Bacteroidetes was almost entirely comprised of Dysgonomonas sp. with modest contributions from Bacteroidales sp. («1\%). In contrast, Firmicutes was a much richer phylum with representatives from several clades and therefore subjected to further scrutiny. These microorganisms have been previously identified in locally anaerobic mining biofilms and sulfate-reducing systems respectively (Boothman et al., 2006; Labrenz and Banfield, 2004). The enrichment of Firmicutes in the deeper reaches of columns WS/S/W (Fig. 5) coincided with an initiation of zinc-sulfur deposition in these regions (Fig. 4A and Table S1). From a monitoring standpoint, an increase in the ratio of Firmicutes to Bacteroidetes in SRBRs may indicate the onset of metal sulfide precipitation in an SRBR when whole community profiles and diversity indices provide limited insight.

An inverse depth trend was observed in columns containing $>10 \%$ alfalfa hay (SA/WA/A) where the average relative abundance ratio of Firmicutes to Bacteroidetes decreased from top to bottom ( $t$-test; $\mathrm{p}<0.01$ ). This coincides with initiation of zinc removal (Table 1 ) in concert with accumulation of SB zinc at the upper parts of these columns (Fig. 2). Importantly, there was a significant positive correlation between the mass of SB zinc extracted per gram of substrate and the ratio of the relative abundance of Firmicutes to Bacteroidetes (Spearman; $\mathrm{R}^{2}=0.6 \mathrm{P}=0.005$ ) across all columns (Fig. 6). While accounting for a modest fraction of the overall Firmicutes community, the average relative abundance of Desulfosporosinus sp., a putative SRB (Ramamoorthy et al., 2006), was significantly greater in alfalfa than woodchip column samples 

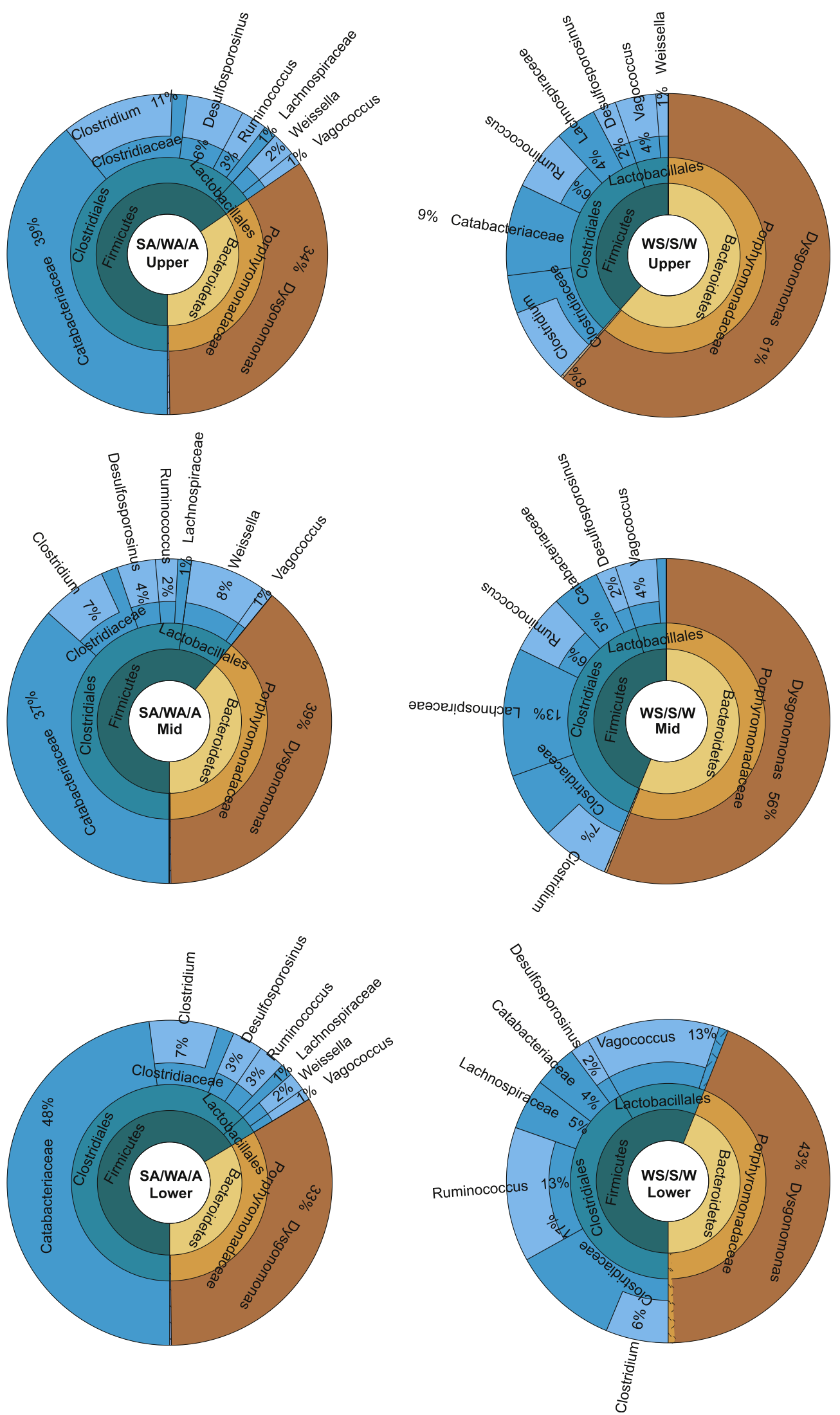

Fig. 5. Firmicutes and Bacteroidetes Abundance Average relative abundance of tiered clades within Firmicutes and Bacteroidetes(Bacteroidales) in labile (SA/WA/A) and recalcitrant $(\mathrm{WS} / \mathrm{S} / \mathrm{W})$ treatments. 


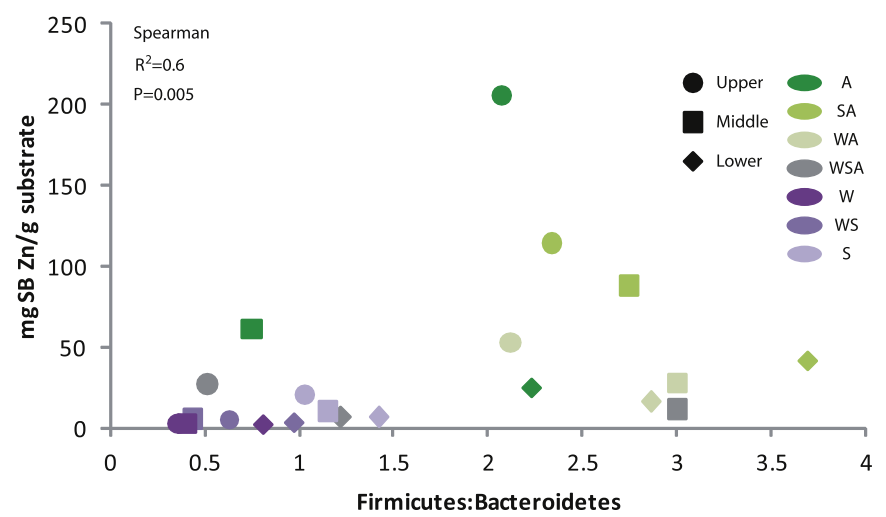

Fig. 6. Firmicutes: Bacteroidetes vs. SB Zinc There is a significant positive correlation between the mass of SB zinc/g of substrate and the ratio of Firmicutes to Bacteroidetes.

(Drennan et al., 2016). In further support of this genus' association with zinc removal, the relative abundance of Desulfosporosinus sp. decreased, albeit not significantly, from top to bottom in the alfalfa columns $(3.2 \% \pm 1.3 \%, 2.3 \% \pm 0.6 \%$, and $1.7 \% \pm 0.5 \%)$.

Column WSA, which exhibited a geochemical transition in zinc removal and precipitation, between 345 and 494 days (Table 1, Fig. 4B and Fig. S4), underwent an analogous ecological transition, but to a lesser extent, where there was an increase in Firmicutes $(26 \pm 7 \%$ to $39 \pm 24 \%)$ and decrease in Bacteroidetes (35 $\pm 8 \%$ to $28 \pm 12 \%$ ) between the two time points (Fig. S3 \& S4). The marked improvement in performance of WSA suggests that the superior performance of alfalfa-containing columns was not only due to its more easily degradable and nutritionally favorable substrate composition, but also due to the selection of a microbial assemblage that could be more advantageous for efficient cellulose degradation with syntrophic contributions to sulfate reduction (Drennan et al., 2016).

\section{Conclusions and implications}

Pilot-scale column systems such as those employed here provide a venue to explore spatial and temporal geomicrobial patterns as they interface with reactor performance attributes. With that in mind, it is important to note that the spatial homogeneity and controlled flow in a pilot-scale column system is not subject to the inherent variability encountered during field implementation. Preferential flow paths (Neculita et al., 2008), freeze-thaw cycles (Hiibel et al., 2011), plant colonization (Gusek and Schneider, 2010), and lateral variability are some of the factors affecting metal-sulfide precipitation in field SRBRs. Unfortunately, coring a field SRBR to query for spatial microbiology is challenging considering the heterogeneous mixture of limestone and organic materials, particles size distribution and saturated conditions present in SRBRs and the disruptive nature of draining that might be needed to obtain solid phase samples. Future larger-scale field implementations that include removable solid phase samples and spatial aqueous sampling ports could better elucidate these lateral biogeochemical signatures.

Our results collectively present a series of systems where spatial metal precipitation patterns are likely driven by inorganic ligand availability as evenly distributed solid-phase organic substrates and an excess of aqueous-phase sulfate do not poise for spatial community stratification. SRBRs are intentionally poised to select for substrate-sourced, organoheterotrophically-driven sulfate reduction. Metal removal, facilitated by this resilient syntrophy, is manifested differently based on recalcitrance of substrate. The importance of organic carbon as a selective driver for SRBRs demand further inquiry into the character of the carbon required for robust performance. For example, a decrease in the freshness index or in the peak ratio (Hansen et al., 2016) would indicate decreasing recalcitrance and lend causality to the conjecture made here that increasing maturity of recalcitrant substrates resulted in more bioavailablity (Fig. 1). The concept that recalcitrant carbon sources require a maturation period before achieving optimal performance should be investigated further to determine if optimal efficacy would be achieved through a mixture of labile and recalcitrant carbon sources. Under this organic substrate regime, labile carbon would initiate and recalcitrant carbon would sustain the availability of organics for respiratory processes.

Zinc removal, precipitation, and elemental association patterns evolved spatially in contrast to the comparative homogeneity observed with respect to community structure and diversity. This was characterized by an early dominance of $\mathrm{ZnCO}_{3}$ precipitates that decreased with time. Immobilization as carbonates was temporally countered by a gradual increase in sulfide-associated precipitation as relevant microbial respiratory processes increased. While perturbations had little effect on overall community composition, the relative abundance of the phyla Firmicutes and Bacteroidetes did exhibit a response to depth. Identifying competitive strategies, in concert with functional -omics analyses may further elucidate observed geochemical feedback to these type of ecological regimes. Lack of spatial variation with respect phylogenetic, diversity, or whole community results does not preclude spatial functional or metabolic variation. Specifically metagenomic and metatranscriptomic analysis of these systems would further inform this potentially massive source of operational variability resulting from functional redundancy, metabolic versatility, and microbial interactions (Vanwonterghem et al., 2014). From a more applied perspective, as the reactor has the same community top to bottom, an efficiently designed system has the potential to homogenously precipitate metal sulfides throughout the column.

\section{Acknowledgements}

This material was based in part through work supported by the U.S. National Science Foundation (CBET-1055396) and the Office of Science (BER) in the U.S. Department of Energy (DE-SC0006997 and DE-SC0016451). Additional financial support was provided by Freeport-McMoRan Inc. (FMI-3321100016) and the J. Gust. Richert Memorial Fund (PIAH/12:57). RA was supported through a Marie Curie International Outgoing Fellowship (PIOF-GA-2012-328397) within the 7th European Community Framework Programme and The Carl Trygger Foundation for Scientific Research (CTS 12:11). The authors thank William Porter for assistance collecting SEM-EDX data, Robert Fields and Gary Zito for assistance with micrograph acquisition, and Kristin Mikkelson for constructive comments during the development of this manuscript. The authors also thank the editor and two anonymous reviewers for their constructive commentary during the publication process.

\section{References}

Almstrand, R., Daims, H., Persson, F., Sorensson, F., Hermansson, M., 2013. New methods for analysis of spatial distribution and coaggregation of microbial populations in complex biofilms. Appl. Environ. Microbiol. 79, 5978-5987. http://dx.doi.org/10.1128/AEM.01727-13.

Almstrand, R., Persson, F., Daims, H., Ekenberg, M., Christensson, M., Wilén, B.-M., 
Sörensson, F., Hermansson, M., 2014. Three-dimensional stratification of bacterial biofilm populations in a moving bed biofilm reactor for nitritationanammox. Int. J. Mol. Sci. 15, 2191-2206. http://dx.doi.org/10.3390/ ijms15022191.

Bekins, B.A., Godsy, E.M., Warren, E., 1999. Distribution of microbial physiologic types in an aquifer contaminated by crude oil. Microb. Ecol. 37, 263-275. http:/ dx.doi.org/10.1007/s002489900149.

Boothman, C., Hockin, S., Holmes, D.E., Gadd, G.M., Lloyd, J.R., 2006. Molecular analysis of a sulphate-reducing consortium used to treat metal-containing effluents. BioMetals 19, 601-609. http://dx.doi.org/10.1007/s10534-006-0006-z.

Caporaso, J.G., Bittinger, K., Bushman, F.D., DeSantis, T.Z., Andersen, G.L., Knight, R. 2010. PyNAST: a flexible tool for aligning sequences to a template alignment. Bioinformatics 26, 266-267. http://dx.doi.org/10.1093/bioinformatics/btp636.

Carlsson, E., Thunberg, J., Öhlander, B., Holmström, H., 2002. Sequential extraction of sulfide-rich tailings remediated by the application of till cover, Kristineberg mine, northern Sweden. Sci. Total Environ. 299, 207-226. http://dx.doi.org 10.1016/S0048-9697(02)00249-8.

Chapman, M.G., Underwood, A.J., 1999. Ecological patterns in multivariate assemblages: information and interpretation of negative values in ANOSIM tests. Mar Ecol. Prog. Ser. 180, 257-265.

Chen, S., Cheng, H., Wyckoff, K.N., He, Q., 2016. Linkages of Firmicutes and Bacteroidetes populations to methanogenic process performance. J. Ind. Microbiol. Biotechnol. 43, 771-781. http://dx.doi.org/10.1007/s10295-016-1760-8.

Clarke, K.R., Warwick, R.M., 1994. Similarity-based testing for community pattern: the two-way layout with no replication. Mar. Biol. 119, 167-176.

Concas, A., Ardau, C., Cristini, A., Zuddas, P., Cao, G., 2006. Mobility of heavy metals from tailings to stream waters in a mining activity contaminated site. Chemosphere 63, 244-253. http://dx.doi.org/10.1016/j.chemosphere.2005.08.024.

Curtis, T., Sloan, W., 2004. Prokaryotic diversity and its limits: microbial community structure in nature and implications for microbial ecology. Curr. Opin. Microbiol. 7, 221-226. http://dx.doi.org/10.1016/j.mib.2004.04.010.

Davey, M.E., O'Toole, G., 2000. Microbial biofilms: from ecology to molecular genetics. Microbiol. Mol. Biol. Rev. 847-867.

Drennan, D.M., Almstrand, R, Lee, I., Landkamer, L, Figueroa, L, Sharp, J.O., 2016 Organoheterotrophic bacterial abundance associates with zinc removal in lignocellulose-based sulfate-reducing systems. Environ. Sci. Technol. 50, 378-387. http://dx.doi.org/10.1021/acs.est.5b04268.

Drennan, D.M., Almstrand, R., Lee, I., Landkamer, L., Figueroa, L., Sharp, J.O., 2017. Pilot-scale columns equipped with aqueous and solid-phase sampling ports enable geochemical and molecular microbial investigations of anoxic biologica processes. Bio-Protocol 7 (1), e2083. http://dx.doi.org/10.21769/BioProtoc.2083.

Gusek, J., Schneider, R., 2010. Passive management of mining influenced water at the Haile Gold Mine, SC. In: Bridging Reclamation, Science and the Community. Presented at the National Meeting of the American Society of Mining and Reclamation, ASMR, Pittsburgh, PA.

Hamarneh, C., 2015. Understanding Early Islamic Mosaic Production: Archaeometric Study of Material from Qasr Mushatta. http://dx.doi.org/10.5281 zenodo.32067.

Hansen, A.M., Kraus, T.E.C., Pellerin, B.A., Fleck, J.A., Downing, B.D., Bergamaschi, B.A., 2016. Optical properties of dissolved organic matter (DOM): effects of biological and photolytic degradation: DOM optical properties following degradation. Limnol. Oceanogr. 61, 1015-1032. http://dx.doi.org/ 10.1002/lno.10270.

Hiibel, S.R., Pereyra, L.P., Breazeal, M.V.R., Reisman, D.J., Reardon, K.F., Pruden, A., 2011. Effect of organic substrate on the microbial community structure in pilotscale sulfate-reducing biochemical reactors treating mine drainage. Environ. Eng. Sci. 28, 563-572. http://dx.doi.org/10.1089/ees.2010.0237.

Himejima, M., Hobson, K.R., Otsuka, T., Wood, D.L., Kubo, I., 1992. Antimicrobia terpenes from oleoresin of ponderosa pine treePinus ponderosa: a defense mechanism against microbial invasion. J. Chem. Ecol. 18, 1809-1818. http:// dx.doi.org/10.1007/BF02751105.

King, A.J., Freeman, K.R., McCormick, K.F., Lynch, R.C., Lozupone, C., Knight, R., Schmidt, S.K., 2010. Biogeography and habitat modelling of high-alpine bacteria. Nat. Commun. 1, 1-6. http://dx.doi.org/10.1038/ncomms1055.

Labrenz, M., 2000. Formation of sphalerite $(\mathrm{ZnS})$ deposits in natural biofilms of sulfate-reducing bacteria. Science 290, 1744-1747. http://dx.doi.org/10.1126 science.290.5497.1744.

Labrenz, M., Banfield, J.F., 2004. Sulfate-reducing bacteria-dominated biofilms that precipitate $\mathrm{ZnS}$ in a subsurface circumneutral-pH mine drainage system. Microb. Ecol. 47 http://dx.doi.org/10.1007/s00248-003-1025-8.

Landkamer, L., Lee, I., Drennan, D.M., Sharp, J.O., Figueroa, L.A., 2013. Substrate and biogeochemical design considerations for sulfate reducing bioreactors. In: Reliable Mine Water Technology. Presented at the International Mine Water Association. International Mine Water Association, Golden, CO, pp. 61-66.

Ley, R.E., Peterson, D.A., Gordon, J.I., 2006. Ecological and evolutionary forces shaping microbial diversity in the human intestine. Cell 124, 837-848. http:// dx.doi.org/10.1016/j.cell.2006.02.017.

Liamleam, W., Annachhatre, A.P., 2007. Electron donors for biological sulfate reduction. Biotechnol. Adv. 25, 452-463. http://dx.doi.org/10.1016/ j.biotechadv.2007.05.002

McGuire, J.T., Smith, E.W., Long, D.T., Hyndman, D.W., Haack, S.K., Klug, M.J., Velbel, M.A., 2000. Temporal variations in parameters reflecting terminalelectron-accepting processes in an aquifer contaminated with waste fuel and chlorinated solvents. Chem. Geol. 169, 471-485. http://dx.doi.org/10.1016/ S0009-2541(00)00223-0.

Méndez-García, C., Mesa, V., Sprenger, R.R., Richter, M., Diez, M.S., Solano, J., Bargiela, R., Golyshina, O.V., Manteca, Á., Ramos, J.L., Gallego, J.R., Llorente, I., Martins dos Santos, V.A., Jensen, O.N., Peláez, A.I., Sánchez, J., Ferrer, M., 2014. Microbial stratification in low $\mathrm{pH}$ oxic and suboxic macroscopic growths along an acid mine drainage. ISME J. 8, 1259-1274. http://dx.doi.org/10.1038/ ismej.2013.242.

Miller, A., Figueroa, L., Wildeman, T., 2011. Zinc and nickel removal in simulated limestone treatment of mining influenced water. Appl. Geochem. 26, 125-132. http://dx.doi.org/10.1016/j.apgeochem.2010.11.009.

Miller, A., Wildeman, T., Figueroa, L., 2013. Zinc and nickel removal in limestone based treatment of acid mine drainage: the relative role of adsorption and coprecipitation. Appl. Geochem. 37, 57-63. http://dx.doi.org/10.1016/ j.apgeochem.2013.07.001.

Mohan, S.V., Rao, N.C., Prasad, K.K., Sarma, P.N., 2005. Bioaugmentation of an anaerobic sequencing batch biofilm reactor (AnSBBR) with immobilized sulphate reducing bacteria (SRB) for the treatment of sulphate bearing chemical wastewater. Process Biochem. 40, 2849-2857. http://dx.doi.org/10.1016/ j.procbio.2004.12.027.

Moore, J.N., Luoma, S.N., 1990. Hazardous wastes from large-scale metal extraction. A case study. Environ. Sci. Technol. 24, 1278-1285. http://dx.doi.org/10.1021/ es00079a001.

Morel, F., Hering, J.G., Morel, F., 1993. Principles and Applications of Aquatic Chemistry. Wiley, New York.

Neculita, C.-M., Zagury, G.J., Bussière, B., 2008. Effectiveness of sulfate-reducing passive bioreactors for treating highly contaminated acid mine drainage: I. Effect of hydraulic retention time. Appl. Geochem. 23, 3442-3451. http:/1 dx.doi.org/10.1016/j.apgeochem.2008.08.004.

Neculita, C.-M., Zagury, G.J., Bussière, B., 2007. Passive treatment of acid mine drainage in bioreactors using sulfate-reducing bacteria. J. Environ. Qual. 36, 1. http://dx.doi.org/10.2134/jeq2006.0066.

Plumlee, G.S., Smith, K.S., Montour, M.R., Ficklin, W.H., Mosier, E.L., 1999. Geologic controls on the composition of natural waters and mine waters draining diverse mineral-deposit types. In: The Environmental Geochemistry of Mineral Deposits Part B: Case Studies and Research Topics, Reviews in Economic Geology.

Ramamoorthy, S., Sass, H., Langner, H., Schumann, P., Kroppenstedt, R.M., Spring, S., Overmann, J., Rosenzweig, R.F., 2006. Desulfosporosinus lacus sp. nov., a sulfatereducing bacterium isolated from pristine freshwater lake sediments. Int. J. Syst. Evol. Microbiol. 56, 2729-2736. http://dx.doi.org/10.1099/ijs.0.63610-0.

Schramm, A., de Beer, D., van den Heuvel, J.C., Ottengraf, S., Amann, R., 1999. Microscale distribution of populations and activities of Nitrosospira and Nitrospira spp. along a macroscale gradient in a nitrifying bioreactor: quantification by in situ hybridization and the use of microsensors. Appl. Environ. Microbiol. 65, 3690-3696.

Sheoran, A.S., Sheoran, V., 2006. Heavy metal removal mechanism of acid mine drainage in wetlands: a critical review. Min. Eng. 19, 105-116. http://dx.doi.org/ 10.1016/j.mineng.2005.08.006.

Steyermark, A., 1966. Introduction to quantitative ultramicroanalysis. J. Am. Chem. Soc. 88 http://dx.doi.org/10.1021/ja00970a070, 4310-4310.

United States Environmental Protection Agency, 2000. Liquid Assets 2000: America's Water Resources at a Turning Point EPA-840-b-00-001.

Vanwonterghem, I., Jensen, P.D., Ho, D.P., Batstone, D.J., Tyson, G.W., 2014. Linking microbial community structure, interactions and function in anaerobic digesters using new molecular techniques. Curr. Opin. Biotechnol. 27, 55-64. http://dx.doi.org/10.1016/j.copbio.2013.11.004.

Zhou, J., Bruns, M.A., Tiedje, J.M., 1996. DNA recovery from soils of diverse composition. Appl. Environ. Microbiol. 62, 316-322. 